\title{
Level of Awareness as Indicators for Healthcare Waste Management in Tertiary Health Facilities in Enugu Metropolis (Nigeria)
}

\author{
U W A, C. U. (MRS) \\ Department of Biological Sciences Federal University Ndufu Alike, Ikwo, Ebonyi State, Nigeria
}

\begin{abstract}
This study was carried out with the aim of investigating the level of awareness of healthcare as indicators of waste management problems by the medical personnel. This involved the survey of a cross section of four tertiary facilities. The study showed that the increase of environmental awareness inputs and safety into healthcare waste management guide will increase the level of awareness of healthcare waste management problems. It indicates that there is urgent need for training and educating all categories of medical personnel to be abreast with the policy in place about the healthcare waste management. Lack of necessary rules, regulations and instructions on different aspects of waste management, non availability of records kept on waste generated and disposed, lack of colour coding and financial allocation are all contributors to average level of awareness on healthcare waste management in Enugu metropolis.
\end{abstract}

Keywords: Investigation, indicators and management

\section{Background of the study}

\section{Introduction}

Healthcare waste is defined as solid or liquid waste arising from healthcare or health related facilities. This waste comprises two fractions, namely hazardous waste and non-hazardous waste as illustrated below:

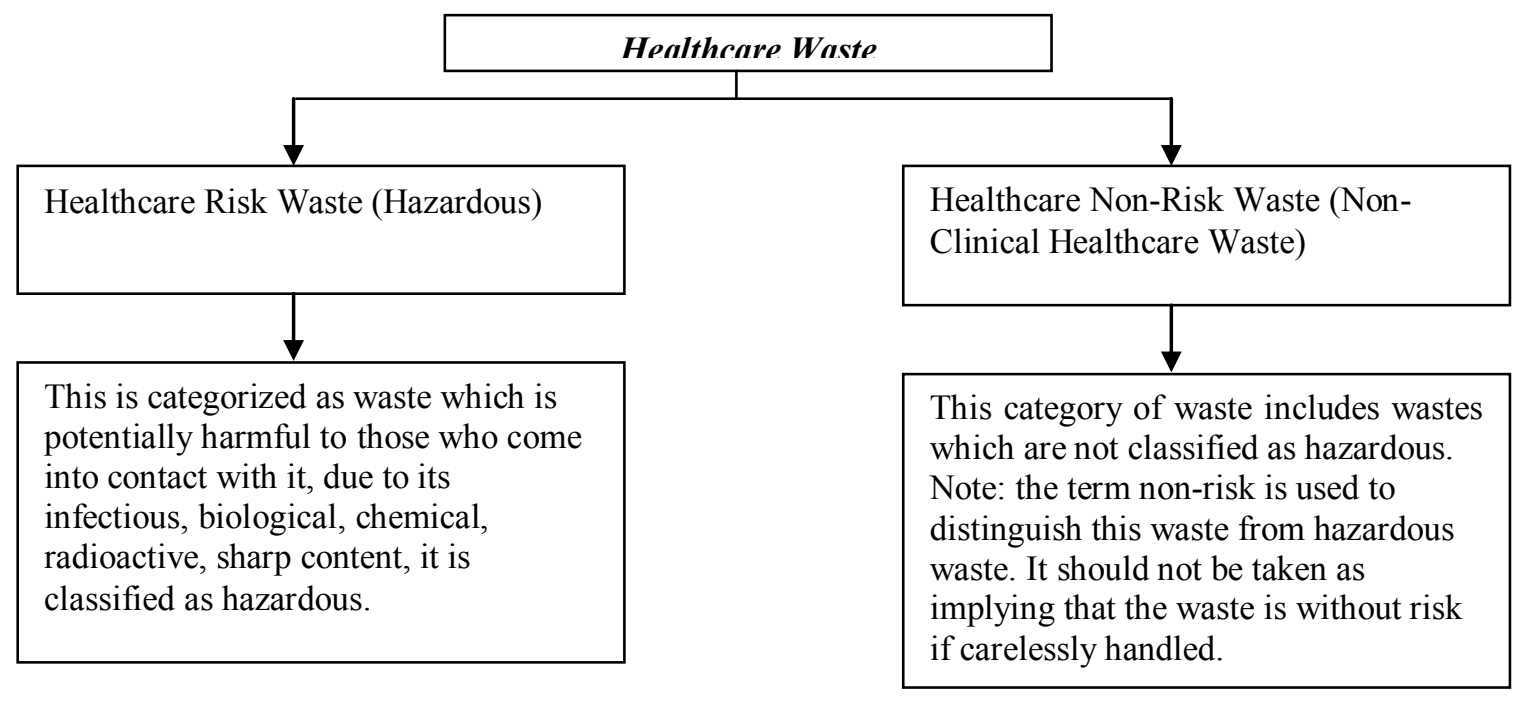

Healthcare waste management (HCWM) inadequacies are increasingly compounding adverse environmental and public health conditions in many developing world areas. In industrialized countries, efforts at innovative and sustainable collection, treatment and disposal of healthcare waste began in the early 1980s.

The driver was the surge in the case of disposable equipment and materials which led to the production of unprecedented quantities of often hazardous waste (FEPA, 1991). Furthermore, the traditional methods of incineration employed in hospitals could not meet the standards of the new clean air legislation of "US Environmental Protection Agency". The outcome was that the hospitals were forced to shutdown their operations.

The Health Services Executives (HSE) report (2011) highlighted a number of areas for awareness improvement, notably the identification of costs and quantities for the disposal of some wastes and the lack of targets and performance measurement in hospital waste management plans.

According to Engineer (2009) who reported that statistics in Angola showed that there is an urgent need to evaluate healthcare waste management and disposal, with special attention to healthcare waste from HIV/AIDS patients and other transmittable diseases such as tuberculosis, he noted further that correct healthcare 
waste management awareness training should include such topics as policy and legislation/regulations definition, human resources, financial resources, allocation and training and awareness programmes for people involved in the healthcare waste subject. The level of awareness; particularly of health workers regarding healthcare waste has been noted not to be adequately documented (Farzadika et al., 2009; Oke, 2005).

The mismanagement of healthcare waste poses health risks to people and the environment by the contamination of the air, soil and water resources. Hospitals and healthcare units are supposed to safeguard the health of the community. Where the healthcare wastes are not properly managed, they can pose even greater threat than the original diseases themselves (PATH, 2009). Poor management of medical waste exposes medical staff, waste handling workers and the surrounding communities to infectious, toxic effects and injuries, a situation that poses a serious health problem in most developing countries (WHO, 1999). Medical wastes must be separated from municipal waste, but in many parts of Africa they tend to be collected along with other waste stream (Kgathi and Bolance, 2001; Tari, 2005). Most hazardous and toxic wastes are disposed on landfill sites with or without safeguards to protect the nearby communities and groundwater from contamination (Hardoy, 1992).

The 1992 Earth Summit in Rio de Janeiro called for action to establish national policy, guidelines and training program for HCW management in all countries of the world (UNCED, 1992). In Nigeria, the government response to the conference has yet to result in a national policy on HCW management. The current national action plans for waste management (as published in Daily Trust Newspapers of 17 September, 2008) did not include participation from health sector. It is therefore not a surprise that healthcare waste management centres are generally lacking at any level of healthcare delivery system. It is also a corporate obligation for waste generators to conduct monitoring, testing or risk assessment and as well put in place policies for safe disposal of medical waste. The procedure for compliance order and violations of this regulation as stipulated in the provision appears ineffective as there is no existing systematic approach to the collection, transportation and disposal of medical waste in Nigeria in spite of the provisions (Slack, et al., 2004, FEPA, 1991).

Studies in Nigeria show that there is not much difference in the level of awareness of healthcare waste management in health facilities. For instance the findings of the study in Lagos by Olubukola reported similarity in waste data and HCW management practice in two general hospitals studied. He showed that they are characterized by a lack of waste minimization/reduction strategies, poor waste segregation practices, lack of instructive posters on waste segregation and disposal of HCW with general waste (Olubukola, 2009).

The aim of this research is therefore to investigate the indicators of level of awareness for healthcare waste management, using 4 tertiary health institutions (Teaching and Specialist hospitals) in Southern States of Nigerian as case study.

\section{Materials And Methods}

This study was carried out between November 2008 and December, 2012 as a cross sectional descriptive and inferential study at four (4) tertiary healthcare facilities in south eastern states of Nigeria based on the modified methods of Townend and Cheeseman (2005) and UNEP/WHO (2005) and subjecting the observations to principal component Analysis.

Based on data obtained from the personnel departments of the hospitals, a total 2577 healthcare staff were obtained. Using the Taro Yamani's (1967) analytical formula, a population of 400 were used for the study.

A total of 400 questionnaires were randomly administered to these healthcare staff, comprising of 9 administrators, 304 Doctors/nurses and 87 orderlies/waste handlers. The questionnaires administered by researchers consisted of questions based on their knowledge and practice of HCW management; knowledge and practice of waste handling, segregation, colour coding, waste treatment and implementation of waste management policies. For proper assessment on healthcare waste management of the hospitals, the key researchers were able to interview the various heads of Departments of the hospitals administration personally and by telephone, to obtain accurate information on the management of the healthcare waste.

The main questions asked were:

i. Available policy and its supervision.

ii. Financial allocation for waste management.

iii. Training of waste handlers.

The waste management awareness performance of the hospital was assessed using a checklist consisting of Eight (8) variables (indicators) namely:

i. Waste management policy in place

ii. Waste management laws available and implemented

iii. Healthcare waste management guidelines

iv. Compliance to best practice

v. Annual awareness training program 
vi. Annual training of personnel on waste management issues

vii. Healthcare waste management policy

viii. Waste management record keeping

The overall performance was the assessed by using the principal component analysis (PCA).

\section{Results}

The objective (to examine the level of awareness of healthcare waste management problems at tertiary health facilities in Enugu metropolis, Nigeria) which was derived from research question (To what extent has the level of awareness of healthcare waste management problems at tertiary health facilities in Enugu metropolis been implemented) was translated to Null hypothesis (the level of awareness of healthcare waste management problems in tertiary healthcare facilities in Enugu metropolis is not significant. Principal component analysis (PCA) is a relatively straight forward method of transforming a given set of variables into a new set of composite variable or components that are orthogonal (that is, uncorrelated) to each other. This produces a varimax rotated set of components. In the light of these characteristics, 8 variables were subjected to principal component analysis was reduced to one (1) component.

Table 1: Summary of the Variables for Level of Awareness

\begin{tabular}{|l|l|l|l|l|l|l|l|l|}
\hline $\begin{array}{l}\text { Level of } \\
\text { Awareness }\end{array}$ & HWM PP & HCWML & CHWM & CBP & YAP & TPWM & CHMP & WMRK \\
\hline$\%$ & $\mathrm{X}_{1}$ & $\mathrm{X}_{2}$ & $\mathrm{X}_{3}$ & $\mathrm{X}_{4}$ & $\mathrm{X}_{5}$ & $\mathrm{X}_{6}$ & $\mathrm{X}_{7}$ & $\mathrm{X}_{8}$ \\
\hline $1-10$ & 22 & 27.5 & 22 & - & 22 & 27.5 & 253 & 5.5 \\
\hline $11-20$ & 15.5 & 31 & 15.5 & 46.5 & 15.5 & 46.5 & 232.5 & 31 \\
\hline $21-30$ & 25.5 & 25.5 & 25.5 & 76.5 & 25.5 & 25.5 & 382.5 & 127.5 \\
\hline $31-40$ & 35.5 & - & 35.5 & 71 & 106 & 35.5 & 284 & 35.5 \\
\hline $41-50$ & 45.5 & 45.5 & 45.5 & 45.5 & - & - & - & - \\
\hline $51-60$ & 55.5 & - & 55.5 & - & - & - & - & - \\
\hline$>60$ & - & - & - & - & - & - & - & - \\
\hline
\end{tabular}

Source: Author's Computation from relevant tables (2012).

Table 2: Matrix Varimax Rotated factor loadings of level of awareness variables in tertiary health facilities in Enugu Metropolis

\begin{tabular}{|l|l|l|l|l|}
\hline Variables & Component I & Component 2 & Component 3 & Commonalities \\
\hline $\mathrm{X}_{1}$ & -.066 & $(.990)$ & .007 & .984 \\
\hline $\mathrm{X}_{2}$ & .206 & .066 & $.911)$ & .877 \\
\hline $\mathrm{X}_{3}$ & .066 & $(.990)$ & .007 & .984 \\
\hline $\mathrm{X}_{4}$ & $(.868)$ & .222 & .109 & .814 \\
\hline $\mathrm{X}_{5}$ & $(.668)$ & .146 & -.645 & .884 \\
\hline $\mathrm{X}_{6}$ & $(.802)$ & -.275 & -.085 & .726 \\
\hline $\mathrm{X}_{7}$ & $.930)$ & -.183 & -.183 & .879 \\
\hline $\mathrm{X}_{8}$ & $(.800)$ & -.054 & -.054 & .674 \\
\hline Eigen values & 3.456 & 2.095 & 1.292 & \\
\hline Percentage variance explained & 43.196 & 26.185 & 16.146 & \\
\hline Cumulative percentage & 43.196 & 69.381 & 85.527 & \\
\hline
\end{tabular}

Source: Statistical Computation (2012)

Table 3: Variable Grouping and Component Loading for Level of Awareness

\begin{tabular}{|l|l|l|l|}
\hline Component & Component Description & Variable Grouping & Component Loading \\
\hline 1 & $\begin{array}{l}\text { Inputs into healthcare waste } \\
\text { management guide }\end{array}$ & Compliance to best practice & .868 \\
& & Frequency of yearly awareness program & .668 \\
& & Yearly trained personnel for WM & .802 \\
& & Compliance to HWM policy & .930 \\
& & Waste management Record keeping & .800 \\
\hline 2 & Compliance to policy in place & Healthcare waste management policy in place & .990 \\
& & Compliance to HWM guidelines & .990 \\
\hline 3 & $\begin{array}{l}\text { Healthcare WM laws available } \\
\text { and addressed }\end{array}$ & Healthcare WM laws available and addressed & .911 \\
\hline
\end{tabular}

Source: Summarized from Table 2 (2012)

The principal component analysis (PCA) was applied and then one (1) component was extracted, which was inputs into healthcare waste management guide comprising of compliance to best practice, frequency of yearly awareness program, yearly trained personnel for waste management, compliance to healthcare waste management policy and waste management record keeping which all loaded very high to make up of that single (1) component "inputs into healthcare waste management guide". This singular component gave eigen values of 
1.000 and total cumulative explained variance of $50.00 \%$ which indicates that the level of awareness is significant in Enugu metropolis (Nigeria) but just on the average (Fig. 1). This shows that $\mathrm{H}_{0}$, was rejected which states that "the level of awareness of healthcare waste management problems is not significant and alternative accepted.

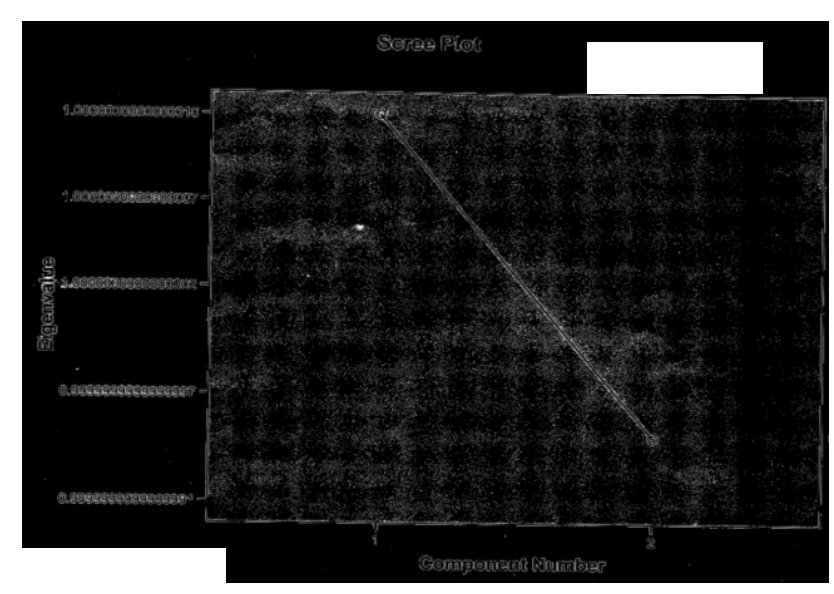

Fig. 1: Level of Awareness

\section{Discussion}

The Null hypothesis which states that "the level of awareness of healthcare waste management problems in tertiary health facilities in Enugu metropolis" is not significant.

\section{Finding:}

The testing of the hypothesis showed that the null hypothesis is rejected and the alternative hypothesis accepted at $50.00 \%$ of total variance explained, thus, it was concluded that the level of awareness of healthcare waste management problems in tertiary health facilities in Enugu is significant, though on the average.

The findings in respect of the hypothesis revealed that the level of awareness of healthcare waste management problems is neither low nor high. The study showed little or no evidence of training and retraining of the waste handlers, neither was there noticeable in house training or seminars conducted for the awareness of deleterious effects of improper management of healthcare waste. These findings did not agree with the findings of Hassan, et al (2008) on the study of the pattern of medical waste management scenario in Ohaka city Bangladesh. Also it was not consistent with the results of Ramandeep, et al (2012), on the study carried out on the awareness of biomedical waste management among dental professionals and auxiliary staff in Amritsar, India, where they observed that the dentists were significantly more aware of the method of waste collection in the hospital and the disposal of various items into different colour - coded basis.

The observed inconsistency disagreement in the findings may be attributed to several factors, some of which are inherent in the unsustainable operation of the Enugu State Waste Management Authority. One major concern is the fact that the financial allocations to the various Heads of departments are small, very minimal. The allocation of less than $0.5 \mathrm{~m}$ Naira per year was found to be too low and inadequate for effective HCW management exercises like hiring of waste disposal trucks and healthcare waste handlers organisation of training workshop seminars and promotion of awareness programmes.

Also, this could attribute to employment of inadequately trained staff (FSLC and GCE/WASC) to oversee the job of waste handling. These staff thus views the waste handling task as just a matter of handling mobs and rakes, without understanding the risk and hazards associated with improper waste handling and disposal of healthcare wastes.

Continuation of this low current performance trend cannot move the system towards sustainability as demanded by the MDGs by 2015. With the continuous increase in number of health facilities and population, coupled with commensurate development, there will definitely be more generation of hospital waste that could be deleterious to health of man and environment. It is therefore pertinent that government and appropriate agencies should pay more attention to the awareness of healthcare waste problems.

\section{Conclusion And Recomendations}

This study has assessed or investigated the level of awareness indicators that must be in place to aid the achievement of high level of awareness. These major components of inputs to healthcare waste management 
guide must be fully available and properly implemented for achievement of sustainability. Due to this average level of awareness, there is common occurance of wanton disregard for the safety of the environment and humans, as wastes (especially hazardous wastes) are not handled with laid down principles and guidelines of waste management and disposal. Existing policies on healthcare waste management must be seen to be implemented fully and adoption of effective health practices that will ensure that those principles are observed. Also the healthcare facilities should be providing supervision by the management on healthcare waste.

\section{Recommendations}

This established that the current awareness programmes of healthcare waste management is on the average, it is therefore recommended that the Enugu State (Nigeria) waste management authority should provide in more financial and material resources to move it towards sustainability, there should be mass $\mathrm{HCW}$ awareness programmes.

1) Implementation of healthcare waste management guidelines at all levels should be advocated.

2) Since good healthy living is vital necessary for all, and it is paramount that it should be accessible to all. Thus, it is recommended that government should as part of their corporate social responsibility, advice all the various networks (MTN, AIRTEL, GLO, ETISALAT, etc) to corporate with government in the dissemination of information on the importance of management of $\mathrm{HCW}$ and the hazards of healthcare waste to man and environment.

3) Use of waste hierarchy like colour coding as an effective way of achieving sustainability.

\section{References}

[1]. Engineer, A. D., (2009): Angola's National Healthcare Waste Management Plan.

[2]. Farzadika M. Moradi A., Mohammdi M. S (2009): Hospital Waste Management Status in Iran: A Case Study in the Teaching Hospitals of Iran University of Medical Sciences. Waste Management Res. 27: $384-389$.

[3]. Federal Environmental Protection Agency (FEPA) (1991): National Interim Guidelines and Standards for Industrial Effluents, Gaseous Emissions and Hazardous Waste Management in Nigeria, FEPA, Abuja.

[4]. Hardoy, J. (1992): Environmental Problems in third world cities, Earthscan, London: Publications.

[5]. Healthcare Services Executives, (2011): Waste Management Awareness Handbook 2011.

[6]. Kgathi, D. I., Bolance, B. (2001): Instruments for sustainable solid waste management in Bobwana, Waste Management Research, $19,342-5$.

[7]. Oke, A. (2008): Management of immunization Solid Wastes in Kano, State, Nigeria. Waste Management, 28:2512 - 2521.

[8]. Olubokola, B. O. (2009): Comparative analysis of healthcare waste management practice in two general hospitals in Nigeria. Available at http://www.ecoweb./com/edi/index.htm. Accessed March, 2012.

[9]. PATH (2009): Achieving effective sharps waste management in GANI lest countries. A proposed approach with estimates of cost 2006. Available at http://www.path.org/tdes/isacheff.surmpdf. accessed 27th July 2009.

[10]. Rizwan, S. A., Baridalyne Norigkynth, Sayeen Kumar Gipta - Apr - June 2011.

[11]. Slack, R. J., Gronow, J. R., Voulvoulis, N., (2004): Hazardous Components of household wastes. Critical Review in Environ. Sci. Technolo., 34 (5): $419-445$.

[12]. Taru, P. and Kururega, A. T. (2005): Solid Medical Waste Management. The Case of Partirenyatwa Hospital, Zimbabwe, Revista Biomedical, 16, $153-158$.

[13]. Townend, W. K. and Cheeseman, C. R., (2005): Guidelines for the evaluation and assessment of sustainable use of resources and wastes management at healthcare facilities. Waste Manage. Res. 23: $398-408$.

[14]. UNCED, (1992): Agenda 21 adopted at the United Nations Conference on Environment and Development (UNCED) Rio de Janeiro, Brazil.

[15]. United Nations Environment Program (UNEP) and World Health Organisation (2005): Preparation of National Healthcare Waste Management Plans in Sub-Saharan Countries - Guidance Manual, WHO document production services, Geneva, Switzerland.

[16]. WHO, (1999): Safe Management of Wastes from healthcare Activities, World Health Organization. 